\title{
Four-Phases Hypothesis of Drama Culture Translation: A Case of Academic Translation Project on Silk Road: The Study of Drama Culture
}

\author{
Fen $\mathrm{Gao}^{1, *}$, FanYang ${ }^{2}$ and Lin Wang ${ }^{3}$
}

School of International Studies, Shaanxi Normal University, Xi'an, Shaanxi, PRC

*Corresponding author. Email: gaojjyy@snnu.edu.cn

\begin{abstract}
Starting from the procedure of applying for Chinese Academic Translation Project sponsored by Chinese Fund for the Humanities and Social Sciences, this paper probes into the four phases of translation for drama culture in Silk Road: The Study of Drama Culture, i.e. initial translation, re-translation, adaptive translation and editing translation, shedding light on Chinese culture's "going global" from a brand new angle. In initial translation, translators focus on the message interpretation of the source text and accurate expression of the target language; in re-translation, the emphasis is paid on the examination and verification of drama and its culture; in adaptive translation, translators cautiously select either domestication or foreignization in order to cater for the interest of target readers; and in editing translation, undergoing six rounds, translators have engaged in the following issues, consistency of terminology, language forms, academic paradigm and publication demands, and so on.
\end{abstract}

Keywords: Chinese academic translation project, Silk Road: The study of drama culture, Initial translation, Re-translation, Adaptive translation, Editing translation.

\section{THE OUTSET OF TRANSLATING SILK ROAD: THE STUDY OF DRAMA CULTURE}

Launched in 2010, the Chinese Academic Translation Project sponsored by Chinese Fund for the Humanities and Social Sciences aims to promote the Chinese culture's "going global" strategy, thus enhancing the appeal of Chinese culture and making China's voice heard by the world. The Chinese Academic Translation Project funds translations that best represent the academic standards of China, embody the essence of Chinese culture and reflect the academic frontiers and excellence of Chinese scholarship. From 2016 to 2018 , the number of projects approved has been increasing yearly: 130 in 2016, 165 in 2017 and 185 in 2018, a total of 480 . These projects cover academic books and journals in 27 disciplines and sectors, such as Marxism-Leninism and social science, CPC history and construction, politics, economy, history, archeology, religion, literature, philosophy, sociology, demography, linguistics, management, education, and so on. The well-funded project draws a large number of applicants, making it of epoch-making significance in the history of
Chinese academic translation.

Against the backdrop of China's needs for both social and academic development, Silk Road: The Study of Drama Culture was approved in 2015, as a part of the Chinese Academic Translation Project sponsored by Chinese Fund for the Humanities and Social Sciences (approval number 15WZS021). The English version has been published by World Scientific Press in Singapore in March 2019 and issued globally. Presently the project of Silk Road: The Study of Drama Culture has been reviewed and concluded in success.

\section{INTRODUCTION TO SILK ROAD: THE STUDY OF DRAMA CULTURE, ITS AUTHOR AND TRANSLATIORS}

Silk Road Science is a new science that came out in the 20th century. It comprehensively studies multiple cultures, including both the humanities about culture, history, religion, ethnicity, archaeology, and physical sciences such as geography, meteorology, geology, biology, etc. Silk Road: The Study of Drama Culture is an academic masterpiece of Silk Road Science. Built on 
the research results, the monograph inherits academic heritage of some 20th-century scholars specializing in drama history (Qu 2012: 384). It is also listed among the books of UNESCO's Silk Road cooperation project and China's Silk Road Research Series funded by the National Publication Foundation. The monograph consists of 14 chapters, more than 500,000 words and 62 delicate illustrations, and is divided into three parts, i.e. studies of traditional Chinese drama, studies of foreign drama and contrastive studies of Chinese and foreign drama. This book embraces strict structure and reasonable layout, echoes drama culture back and forth and enjoys harmonious coexistence of pictures and texts. It is a well-organized culture-research monograph intelligible to people of all walks of life. Yu Zhongjie (2013: 152-154) noted that this book is a pioneering work of the Silk Road drama research, which breaks through the traditional concept that western culture is the mainstream and drama of Han ethnic group as the center. Applying academic methods of integrating literature, cultural relics and field investigation, the author studies the drama culture of nations along the Silk Road from the perspective of cultural anthropology.

Professor Li Qiang, author of Silk Road: The Study of Drama Culture, is a doctoral supervisor at the School of Chinese Languages and Literature in Shaanxi Normal University, a member of China Theatre Association and the secretary-general of China Western Art Research Association. Awarded more than 10 times, he has chaired and participated in various academic projects and written over 20 academic works. Among them, Silk Road: The Study of Drama Culture, won sponsorship from National Publication Foundation and from Chinese Academic Translation Project sponsored by Chinese Fund for the Humanities and Social Sciences.

Professor Gao and her translation team translated Silk Road: The Study of Drama Culture into English. As an associate professor at the School of International Studies in Shaanxi Normal University, Prof. Gao mainly engages in the research of translation theory and practice. She has issued more than 10 papers in both Chinese and foreign academic journals and published 10 translations in the last few years, including Blue Book Of China, Things That Nobody Knows, The Story of the Bible, The Prince, etc. In 2009 and 2015, Prof. Gao respectively paid her academic visits to University of Massachusetts in US and University of Nottingham in UK, which laid a solid foundation for her translation ability and academic research. Professor Gao's a great amount of translation practices facilitated the birth of her translated work with its high quality in 2019, namely Silk Road: The Study of Drama Culture.

\section{DECLARATION AND APPROAVAL OF TRANSLATING SILK ROAD: THE STUDY OF DRAMA CULTURE}

Silk Road: The Study of Drama Culture is an academic masterpiece with great academic value and broad social impact. As part of the Silk Road Cultural Heritage Project jointly developed by UNESCO and China, this book integrates traditional Chinese dramatic literature of all ethnic groups with cultures along the Silk Road and channels it to the world drama cultural system. It seeks to establish a new discipline, namely Silk Road drama science, so as to fill the academic gaps between China and other countries in term of cultural exchanges. Once published, the book stirred China's academic community. In 2011, 2012, and 2013, it won three awards in sequence from Education Department of Shaanxi Province, Shaanxi provincial government and the Chinese Ministry of Education. Therefore, translating and spreading Silk Road: The Study of Drama Culture is helpful to push the Chinese dramatic literature and art to the world's performing arts platform and bridge eastern and western civilizations. In addition, its translation is also in line with Chinese academic works' "going global" strategy and will fully demonstrate the advantages of the "Belt and Road Initiative". Therefore, the monograph is well worth applying for the Chinese Academic Translation Project sponsored by Chinese Fund for the Humanities and Social Sciences.

Under the "Belt and Road Initiative", Professor Gao actively communicated with the author of the original work over the feasibility and operability of translating Silk Road: The Study of Drama Culture and obtained school funding. Further, she along with her team succeeded in applying for the funding from Chinese Fund for the Humanities and Social Sciences. They communicated with the publishing house of the original work on copyright issues, contacted foreign authoritative publishing houses, prepared translation samples, filled in declaration forms, worked on the details of the publishing contract, completed materials about the academic level and influence of Silk Road: The Study of Drama Culture and submitted related papers to the National Office for Philosophy and Social Sciences. Finally, the project was successfully approved.

\section{TRANSLATING DRAMA CULTURE IN SILK ROAD: THE STUDY OF DRAMA CULTURE}

\subsection{Initial Translation: Interpretation of the Original Work and Translation Expression}

Obtaining the project approval from Chinese Academic Translation Project sponsored by Chinese Fund for the Humanities and Social Sciences was the 
very first step. The translation team was clearly aware that when the project was reviewed, the translation quality was laid great stress. Bearing this consensus in mind, the translation team identified uniform translation principles and standards. At the same time, they studied the original work with Professor $\mathrm{Li}$, author of the original work, seeking to interpret the profound connotation of the book from different perspectives of, namely, the author, the translators and readers. The translation team straightened out the logic and structure of the original before translating and had a deep understanding of the developing course, historical and cultural background, as well as national and regional differences of drama evolution. After an all-round consideration (including the translators' ability, time limit, degree of difficulty, knowledge base and subject background of each translator), the project director assigned tasks to members in the team and required them to translate specific chapters in accordance with the translation principles and standards established earlier.

One of the difficulties in understanding the original work was that in some cases, there is no interpretation of the original classical Chinese text. Therefore, it was difficult for translators to accurately grasp the meaning of the original. When facing such problems, members of the translation team would have a discussion.

For example, there is one sentence on page 377 of the original work: “西亚之火袄教、景教、摩尼教, 亦 于唐代, 先后盛于长安。综此各方面而言, 有唐之西 京, 亦可谓极光怪陆离之致矣。” There are two “亦” (Yi) in these two sentences. The second “亦” (Yi) has the same meaning as "also", but the meaning of the first “亦” (Yi) was not clear. After consulting the dictionary, the translation team addressed the following interpretation of “亦” (Yi):

1) adv., also, too, the same;

2) and;

3) just, only;

4) modal particle to emphasize or show euphemism;

5) a surname.

After discussion, team members reached a consensus: the first “亦” (Yi) is a modal particle, emphasizing that Zoroastrianism, Nestorianism and Manichaeism originated in the Tang Dynasty and later flourished in Chang'an. Xijing in the Tang Dynasty refers to Xi'an nowadays. The team members also talked over the coherence and wording of the translation. They believed that the main information of the original should be clearly elaborated, without being restrained by the direct speech from the original, and that it is not necessary to completely follow the manner of the original but feasible to paraphrase. Translators could give full play to their subjectivity and appropriately delete, rewrite and reprocess the original text to maximize the appropriacy, correctness and smoothness of the translation. The translation team also had a thorough communication with Professor Li Qiang, author of the original work and obtained his consent. Finally, the translation of these two sentences goes like: "He pointed out that these religions took their shapes during the Tang dynasty and bloomed one after another in Chang'an. In terms of all the various aspects, Xijing was a place portrayed as quite poly-basic yet odd it could be (Gao 2019: 779)". Thus, the major idea of the original is clearly paraphrased, which is very helpful for the target readers to accurately grasp the description in the original.

\subsection{Re-translation: Verification and Validation of the Drama Culture}

After the initial translation was completed, each member of the translation team needed to solve various details. These detailed problems must be classified, analyzed, discussed, and concluded with a final solution, which can be roughly divided into two categories: one is to verify and validate the relevant allusions, and the other is to check and confirm the specific meaning of those relevant quotations.

Verifying and validating relevant allusions requires a great deal of work. The translator is obliged to resort to various academic books, reference books and online resources for verification. If necessary, the translator also needs to consult experts in drama or related disciplines. The verification of "Nine Surnames of Zhaowu" (Li 2009: 374) went through a long process. “Zhao Wu Jiu Xing Guo” (昭武九姓国) is actually a general term used by historians in Wei, Jin, Southern and Northern Dynasties and Sui and Tang Dynasties, for the nine surnames in the basins of Amu Darya and Syr Darya in Central Asia. According to the "New Book of Tang", these nine surnames are Kang, An, Cao, Shi, Mi, He, Huoxun, Wudi and Shi. The translator found a translation online as "Zhao wu toghuzghuz countries". And from other historical materials, the translator noticed that someone used "Toghuzghuz" as a general term for the nine surnames. After a thorough analysis, the translator decided that such translations were obviously too academic or abstract for the target readers to understand the essential information of the term. Thereby, after verifying the history of this period plus a proper understanding, the translator initially translated it into "Nine families of Zhaowu, Nine names of Zhaowu, Nine countries of Zhaowu", etc. A further discussion among members of the team has concluded that the above translations were too lengthy to meet the principles of conciseness and clarity. Therefore, they deleted the "countries", merged "Zhao" with "wu", and ignored "period" (时期), integrating them into "Nine Surnames of Zhaowu” (Gao 2019: 775). 
To verify and validate the specific meaning of relevant quotations, the translator needs to correctly understand and interpret the original text and to timely converse with the author, so as to choose a translation with proper wording, expression and consistency. For example, there is such quotation in the original work, “......此时景教大走红运 “法流十道，国富元休，寺满 百城，家殷景福。” (Li 2009: 378). Six four-character words such as “大走红运, 法流十道, 国富元休, 寺 满百城, 家殷景福” demonstrate “the religion saw its climax". Whether the translation can reproduce the paratactic phrases or sentence patterns of the original text is an important factor to consider. “大走红运” was then translated into "saw its climax", which pertinently re-presents the prosperity of Nestorianism at that time. Yet, it is difficult to translate other four-character words into fixed-structured and paratactic English sentences. On top of this, if the "theme + rheme" four-character words are translated into sentences, it would be very verbose. The translator finally put these four-character words into nominative absolute construction, to be concise and clear on the one hand, and syntactically consistent on the other hand. Also, "spreading", "prosperous", "scattering", "affluent" and "satisfied" show appropriate wording.

During the re-translation process, verifying and validating specific information calls for the translators' responsibility and teamwork. This time, the focus is mainly on the translation of terminology and quotations, because translators already have a considerable understanding of the original work. Translators need to not only convert these terminology and quotations precisely, but also make the sentences and contexts logical, the language coherent and the choice of words accurate. An important point to realize here is that re-translation is not just a simple modification of the first translation but a new round of translation based on the initial job. Sometimes the fixed thinking and routine should be abandoned to leave a space for translators to rethink, reinterpret, re-explore and re-translate.

\subsection{Adaptive Translation: Choice between Domestication and Foreignization}

After completing the initial translation and re-translation, the translation team also needs to conduct the adaptive translation which mainly focuses on the choice of translation strategies, i.e. domestication or foreignization. Specifically, translators must spend more time and energy in considering various factors and modifying the initial translation and re-translation, so as to make them as easy as possible for the target readers to comprehend the major content, cultural connotations, expression forms and historical development. For example, in the title 《隋书·音乐志》 ("Records of Music” in the Book of Sui:), “音乐志” actually means records of music that have been included, so it is more appropriate to translate it into Records of Music by domestication, which can be easily accepted by the target readers. Yet, from another perspective, the fundamental purpose of Chinese Academic Translation Project is to propel Chinese culture to "go global", and make the Chinese voice heard by the world, so that the world will know China better. All these serve to enhance the appeal and charisma of Chinese culture. As foreignizing translation sometimes is more in line with these intentions and purposes, "transliteration + annotation" is thus one of the important translation methods that can retain the flavor of the original. For example:

“As 'Records of Music' in the Book of Sui observes: $\mathrm{He}$ also ordered men and women of Wuwei (in the east of Hexi Corridor) and Zhangye (in the middle of Hexi Corridor) to dress up and swarm to the streets. The carriages and horses filled streets and lasted for dozens of miles, displaying the strength of the Central Plains." (Li 2009: 380)

Here, “Wuwei”(武威) and “Zhangye” (张掖) are two place names, transliterated into Chinese Pinyin "Wuwei" and "Zhangye". To make Western readers know the specific location, annotations have been added, namely Wuwei (in the east of Hexi Corridor) and Zhangye (in the middle of Hexi Corridor). This method also goes to some classic works' and drama names' translation: Meng Yuanlao's 《东京梦华录》 (P133) is translated into Dong Jing Meng Hua Lu (or Reminiscences of Eastern Capital) (P308),杂剧 (P234) is translated into Zaju (Variety Plays) (P516), and 元曲 (P239) into Yuan Qu (or Tune), etc.

Domestication or foreignization has always been weighed by the translation team all the time. Eventually, the translation principle of Silk Road: The Study of Drama Culture is: to use domestication based on the essence of the original; to use free translation to cater for the target readers; and to use transparent language to minimize the target readers' sense of strangeness. All is known that translators shoulder the responsibility to interpret some information that may be difficult for the target readers to understand, so that the target readers can naturally read and easily comprehend the translation. At the same time, under the guidance of foreignization, "transliteration" or "transliteration + annotation" should also be used appropriately, aiming to carry forward the Chinese culture and introduce China and Chinese drama culture to the world. For the translation of some historical materials, the translator can refer to the existing translation works; for those historical materials that are not representative, translators can abridge them. 


\subsection{Editing Translation: Unification of Language Format, Academic Norms and Publishing Requirements}

Even though the original text has undergone the initial translation, re-translation and adaptive translation, the translation quality still may not be perfect. It is not just a simple process of proofreading but a mission of unification. The team leader divides the editing translation into three steps. First, to urge the translators to submit his/her own translation on time and sort them by chapters according to the sequence of the original work. Second, to standardize and unify the character attributes of translation, including size, font, line spacing, margins, title format, quotation format, footnote form, illustration position, punctuation, etc. Third, to comb the wording forms, including spelling, vocabulary selection, figure of speech, expression, etc.

When proofreading, the director needs to check the translation word by word, modify the spellings of words and check the accuracy of the translation, the appropriateness of the adaption, the overall consistency, the standardization of the format, and so on. The director also needs to turn back to double check the previous translation and compare the translations between chapters, so as to avoid situations where previous and current translations have inconsistencies and differences. Plus, the team leader needs to use modern editing methods such as searching, replacing, annotating, marking, underlining, area highlighting to help translators quickly find and solve problems. For example, PDF has all the above functions to meet all the needs. When proofreading, the team leader mainly emphasizes on solving the following questions: 1) Whether to use "the" or not before a noun; 2) a transliterated term of noun should written separately or together; 3) the selection of superordinates or hyponyms.

For instance, the Chinese character “戏” (Xi) has three counterparts in English: opera, drama and play. The original work does not seem to distinguish them clearly. Noticing this problem, the translator immediately consulted experts. Finally, "drama" was chosen as the abstract and general term referring to all kinds of drama or drama arts. Thus there are the following translations: 西域戏剧 - Western Regions drama, 东方戏剧 — eastern drama, 梵剧 - Sanskrit drama, 罗马戏剧—Roman drama, etc; “play” refers to a specific form of drama, specifically "acting". Corresponding translations include: 偃师戏一Yanshi play，乐舞戏-Music-dance play，柘枝队戏一Zhezhi Group play, 马戏一horse play, 傀儡戏—puppet play, 歌舞戏—-song-dance play, etc; “opera” was chosen to mainly refer to those performing arts along with singing on the stage, so there are the following translations such as 东方戏曲—eastern opera, 佛教戏曲一Buddhist opera, 赛戏一Sai opera, 目连戏一Muliangalyayana opera, etc.

After six rounds of revisions by the major translators, the English version Silk Road: The Study of Drama Culture was finally completed. The proofreaders and World Scientific Press in Singapore sent continually the manuscript through Wetransfer. Each proofreading contained the joint efforts from both parties, and created improvement on the previous version. The editing translation lasted for one year, once every two months on average. This workload and intensity were astonishing. During proofreading, the translators extracted key words and terms from each chapter and sorted them in sequence, preparing for the index at the end of the book, which made it convenient for the readers to retrieve the relevant chapters. Certainly, the extraction of key words and terms itself was another check and review.

\section{CONCLUSION}

The translation of Silk Road: The Study of Drama Culture lasted four years, and the translators struggled for countless days and nights. This book, thereby incorporates endeavour and efforts of the project director and the whole translation team. Before it was officially published, it had been verified, supplemented, modified, revised and re-translated through four stages: initial translation, re-translation, adaptive translation and editing translation. After that, it undergone six rounds of proofreading, focusing on three aspects: content, language and format. Finally, the academic translation of 500,000 Chinese characters was published in the English version of 854 pages, which proved to be a huge translation project calling for arduous work. More importantly, at the same time, it was also a very meaningful translation project.

To sum up, the translation of Silk Road: The Study of Drama Culture responds to China's call for the "Belt and Road Initiative", contributes to Chinese Academic Translation Project and sets a good example to promote the exchange among Chinese culture and world cultures. It is hoped that the translation practice of this book can provide reference for more translators, and that more translators, taking the responsibility of spreading Chinese culture, could translate more excellent Chinese works of literature into other languages, so as to undertake cultural exchange and consolidate Sino-foreign relations. Accordingly, China's cultural soft power will be greatly enhanced and China will play an even more shining role in the world arena.

\section{ACKNOWLEDGMENTS}

This article is sponsored by Chinese Fund for the Humanities and Social Science (approval number 15WZS021). Its English version has been published by 
World Scientific Press in Singapore, and now the project of Silk Road: The Study of Drama Culture has been successfully reviewed and concluded.

\section{REFERENCES}

[1] Qu L. Y., New Expansion of The Study of Drama Culture Along the Silk Road: On Li Qiang's New Book - Silk Road: The Study of Drama Culture [J]. Traditional Chinese Drama Research, 2012, (1): 381-384.

[2] National Office for Philosophy and Social Sciences. Announcement on Applying for Chinese Academic Translation Project sponsored by Chinese Fund for the Humanities and Social Sciences, 2016.

[3] National Office for Philosophy and Social Sciences. Announcement on Applying for Chinese Academic Translation Project sponsored by
Chinese Fund for the Humanities and Social Sciences, 2017.

[4] National Office for Philosophy and Social Sciences. Announcement on Applying for Chinese Academic Translation Project sponsored by Chinese Fund for the Humanities and Social Sciences, 2018.

[5] Yu Z. J., The Pioneering Book of The Study of Drama Culture Along the Silk Road: On Li Qiang's New Book - Silk Road: The Study of Drama Culture [J]. Comparative Literature in China, 2013, (3): 152-154.

[6] Li Q., Silk Road: The Study of Drama Culture [M]. Urumqi: Xinjiang People' Press, 2009.

[7] Gao F., Silk Road: The Study of Drama Culture [M]. Singapore: World Scientific, 2019. 